\title{
Solar Cycle Response in the Horizontal Force of the Earth's Magnetic Field
}

\author{
B.N. BHARGAVA and A. YACOB \\ Colabà and Alibag Observatories, Bombay-5, India \\ (Received September 10; revised December 9, 1968)
}

\begin{abstract}
The solar cycle line has been resolved in the horizontal force by power spectrum analysis using 120 years' data of Colaba-Alibag. Having established the presence of a large signal, the variation and phase in relation to solar cycle have been computed from the data of eight observatories by the application of an appropriately designed band-pass numerical filter. The response in the horizontal force has been found to be larger and more uniform than estimated earilier. At most of the stations, the response was still greater during peaks of odd solar cycles suggesting a 22-year variation in the field. An unexpected 17 to 18 year cyclic variation has also been noticed in the autocorrelation function of the data series of Colaba-Alibag. The data of this station, after removal of the secular variation, also suggest the presence of an 80 year cycle in the horizontal force.
\end{abstract}

\section{Introduction}

The study of long-period magnetic variations provides a direct method of estimating the electrical conductivity of the lower part of the earth's mantle. Banks and Bullard (1966) computed the conductivity from the annual term in the horizontal and vertical force of the earth's magnetic field. Periods corresponding to 11-year sunspot cycle have been utilized by Yukutake (1965) to compute the conductivity at a depth of about $1600 \mathrm{~km}$. While attempts to resolve the 11-year line in the surface magnetic data by power spectrum analysis have not met with success (Eckhardt et al., 1963), time variations of the field or of the indices of magnetic activity of periods corresponding to a solar cycle and a 22-year cycle have been examined by Moos (1910), Wasserfall (1941), Chapman and Bartels (1940), Vestine et al. (1947), Chernosky (1966), Fisk (1931), Pramanik and Ganguli (1954) and Yukutake (1965). It has been well established that the horizontal component of the field is smaller during periods of high solar activity. The investigations of Fisk (1931) to compute the solar cycle variation of the geomagnetic field, RV, from the data of 10 observatories were extended by Vestine et al. (1947) with more extensive data. The methods generally adopted for deriving RV consist of fitting a sinusoidal formula or a power series to the data and computing the departures of the observed data from those computed from the best-fitting sinusoidal series or polynomials. Fitting a simple polynomial to a long data series is, however, not desirable as this may result in large errors creeping into the residuals. The detection of a periodic solar cycle component of an anticipated amplitude of a few to few tens of gammas in the field in the presence of a large, and often irregular, secular change requires careful elimination of 
the trend. The continuum 'noise' in the data in the vicinity of frequency of $1 / 11 \mathrm{cycle} / \mathrm{year}$ may also be of the order of several gammas. Periodic signals of large amplitude are also believed to exist in the series and render it difficult to isolate the signal corresponding to a solar cycle. Besides, a reliable estimation of the 11-year signal requires data extending over many solar cycles. Pramanik and Ganguli (1954), using method of fitting polynomials to horizontal force and declination data from several stations, failed to obtain a solar-cycle component in these elements. In the course of an extensive investigation to compute the 11-year component in the $X, Y$ and $Z$ components of the field, Yukutake (1965) obtained the solar cycle variation in these elements. His method of estimating the amplitude of the component consisted of numerical differentiation of the time series of mean annual values to reduce the long as well as short period variations. This was followed by an application of a high-pass digital filter to achieve further reduction of the long-period variations. The amplitudes were computed from an integration of the Fourier coefficients of time derivatives of the components, $X, Y$ and $Z$. The amplitudes of the 11-year variation in the north component were, however, found to have a considerable scatter, the values varying from 2 to $17 \gamma$.

In the present investigation an attempt has been made to first test the reality of the 11-year signal using a long data series from Colaba-Alibag. After establishing that the power spectrum yielded a significant 11-year signal, the data of eight selected observatories with long and systematic observations have been processed to compute the solar cycle variation using digital filters. The application of digital filtering to extract information by elimination of undesired signals and constructing desired signals has been used extensively in recent years and several methods of digital filtering have appeared in the literature. These methods are extremely useful when the periodicity being investigated is not of a constant amplitude and when it may be present over one interval of years and absent during another. The computations here have been restricted to the horizontal force.

\section{Observatories and data}

Annual mean values of the horizontal force at eight stations have been obtained from

Table 1. List of Observatories

\begin{tabular}{|c|c|c|c|c|}
\hline \multirow{2}{*}{ Station } & \multicolumn{2}{|c|}{ Geographic } & \multirow{2}{*}{ Period of Data } & \multirow{2}{*}{ Remarks } \\
\hline & Latitude & Longitude & & \\
\hline Colaba-Alibag & $18^{\circ} 38^{\prime} \mathrm{N}$ & $72^{\circ} 52^{\prime}$ & $1848-1967$ & Data reduced to Alibag \\
\hline Honolulu & $21^{\circ} 19^{\prime} \mathrm{N}$ & $202^{\circ} 00^{\prime}$ & $1902-1965$ & \\
\hline San Fernando & $36^{\circ} 28^{\prime} \mathrm{N}$ & $353^{\circ} 48^{\prime}$ & $1891-1965$ & \\
\hline Cheltenham & $38^{\circ} 44^{\prime} \mathrm{N}$ & $283^{\circ} 09^{\prime}$ & $1901-1956$ & \\
\hline Coimbra & $40^{\circ} 13^{\prime} \mathrm{N}$ & $351^{\circ} 35^{\prime}$ & $1867-1965$ & \\
\hline $\begin{array}{l}\text { Greenwich- } \\
\text { Abinger- } \\
\text { Hartland }\end{array}$ & $51^{\circ} 28^{\prime} \mathrm{N}$ & $0^{\circ} 00^{\prime}$ & $1861-1966$ & Data reduced to Greenwich \\
\hline $\begin{array}{l}\text { De Bilt- } \\
\text { Utrecht- } \\
\text { Witteween }\end{array}$ & $52^{\circ} 06^{\prime} \mathrm{N}$ & $5^{\circ} 11^{\prime}$ & $1891-1965$ & Data reduced to De Bilt \\
\hline Oslo & $59^{\circ} 55^{\prime} \mathrm{N}$ & $10^{\circ} 43^{\prime}$ & $1843-1930$ & \\
\hline
\end{tabular}


the thesaurus compiled by Fleming and Scott $(1943,1944)$ as well as from Pramanik and Ganguli (1954) and Royal Observatory Bulletin No. 134. Using simultaneous observations over two years the extensive data from Colaba and its successor Alibag, extending back to 1847, have been reduced by Pramanik and Ganguli (1954) to form a long homogeneous series from 1875 to 1949 and have been used here after extending the series back to 1848 and forward upto 1967. A list of observatories together with the period for which mean annual values from each have been used is given in Table 1.

\section{Computations}

The time series consisting of mean yearly values of the horizontal force is known to have a large 'trend' arising predominantly from secular variation. For instance, the rate of increase of the horizontal force at Alibag has been of the order of $49 \gamma$ per year between 1926 and 1954. The trend constitutes concentration of large power near zero frequency and is a source of leakage to higher frequencies. It has, therefore, to be reduced as much as possible before further analysis. The most convenient way to do this is by the application of digital filters. The design of a numerical filter consists in determining the shape of the desired data window in the frequency domain followed by the computation of weights of the filter such that the response of the filter is as close as possible to the desired response. The closeness of the response of a filter to that of an ideal filter is a function of its size. However, loss of data at either end of the series increases with the size of the filter and a compromise has to be made between the desired response characteristics and the extent to which the loss of data can be tolerated. In the present case sine-termination filters (Behanon and Ness 1966) which have a small overshoot near the cut-off were adopted to compute the trend as well as to remove it. A 25 point ultra-low pass filter with responses of 0.96, 0.70 and 0.41 at $1 / 100,1 / 33$ and $1 / 22$ cycle/year respectively and with practically zero response for frequencies $\geqq 1 / 11$ cycle/year was used to compute the 'trend'. The frequency response of the filter is shown in Fig. 1 (Curve L). The secular variation computed by the application of this filter for the eight stations is shown in Fig. 2. The same filter was used as a high-

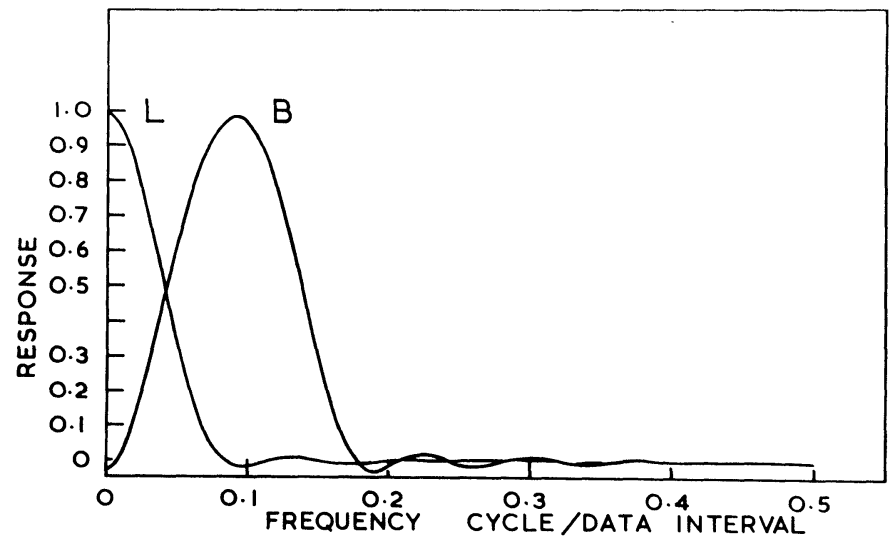

Fig. 1 Frequency response of 25-weight ultra low pass filter (L) and of 25-weight band pass filter (B). 
pass filter to eliminate the 'trend' after suitably modifying the weights according to the scheme,

$$
\begin{aligned}
& W_{0}{ }^{1}=1-W_{0} \\
& W_{k}{ }^{1}=-W_{k}
\end{aligned}
$$

where $W_{0}$ and $W_{0}{ }^{1}$ are the central weights of the low-pass and high-pass filters and $W_{k}$ and $W_{k}^{1}$ are the respective $k^{t h}$ weights.

Annual values of horizontal force at Colaba-Alibag from 1848 to 1967, reduced to 96 values after the application of the trend-elimination filter, are shown in Fig. 3 (continuous line) together with the response of the filter. The autocorrelation function of the trend-free series with a maximum lag of 20 and the power spectrum, computed by the method outlined by Blackman and Tukey (1959), are shown in Fig. 4. The spectrum shows an extremely small peak between values of the frequency parameter, $h$, from 2 to 4 presumably corresponding to a period of 11 years. The spectrum, however, shows that large power was still present near zero frequency. Further reduction of power at low frequencies was therefore tried. This was done by the application of a modified high-pass filter whose response for periods from $\propto$ to 25 years was practi-

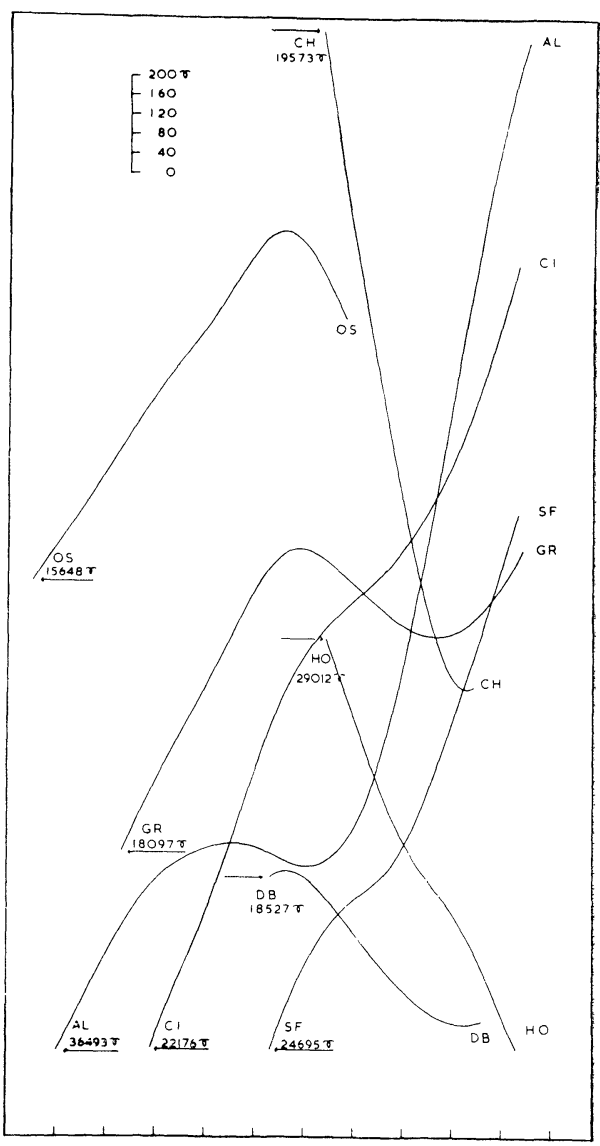

$1950 \quad 1860 \quad 1870 \quad 18801880 \quad 1900 \quad 1910 \quad 1920 \quad 930 \quad 1940 \quad 1950 \quad 1960$

Fig. 2 Secular trend in annual mean values of $H$ at eight stations, Colaba-Alibag (AL), Honolulu (HO), San Fernando (SF), Cheltenham (CH), Coimbra (CI), Greenwich-Abinger-Hartland (GR), De Bilt-Utrecht-Witteween (DB), Oslo (OS). cally zero. Even though the response of the filter at a frequency corresponding to period of 11-years was only 0.71 , the autocorrelation of the series showed three large cyclic components, corresponding to 5.5, 11 and an unexpected 17 or 18 years. The power spectrum of the series after the application of this filter together with the autocorrelogram and response of the filter is shown in Fig. 5. With power in the low frequencies practically eliminated, the line corresponding to solar activity cycle is very well resolved and establishes the presence of the signal in the horizontal force associated with solar cycle. The peak power density is nearly $18 \gamma^{2}$ per cycle/40 years and when recoloured for the filter factor of 0.71 at this frequency yields an amplitude of about $6 \gamma$ over the solar cycles 11 to 18 . It still, however, gives no indication of the phase of the response in relation to solar activity nor does it indicate how uniform the response was in its amplitude between 1860 and 1955, a period corresponding to about nine solar cycles. 


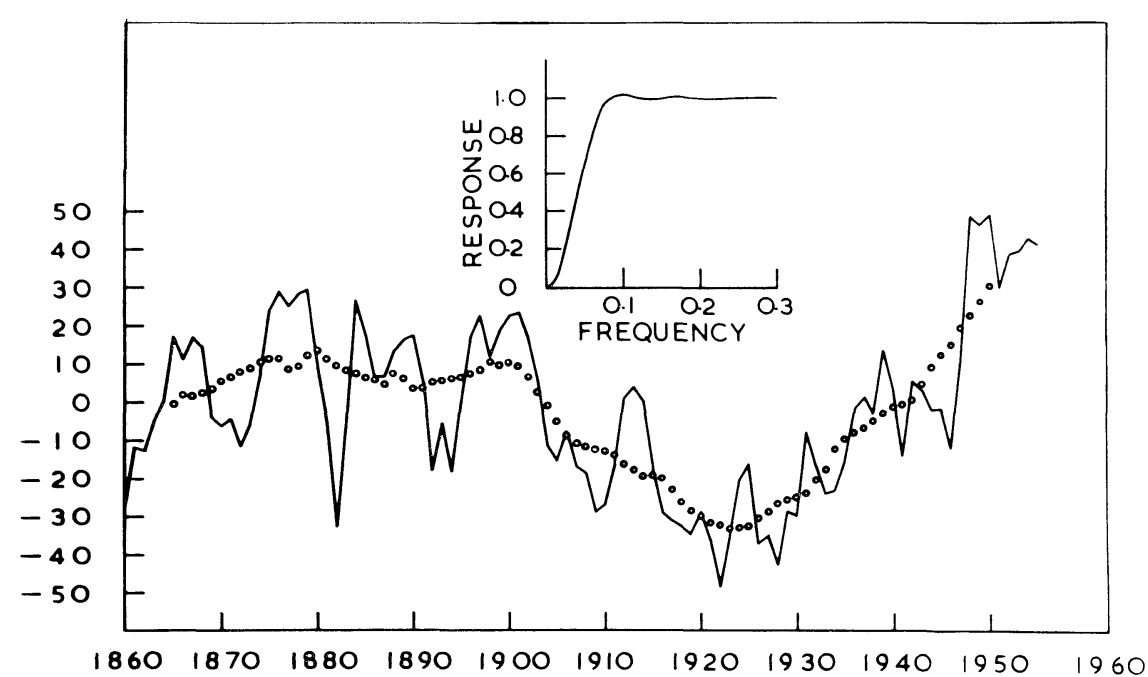

Fig. 3 Annual mean values of $H$ at Alibag (Continuous line) after application of the 25weight high pass filter. (frequency response of the filter also shown in the figure). Values indicated by small circles are 11-year overlapping averages.

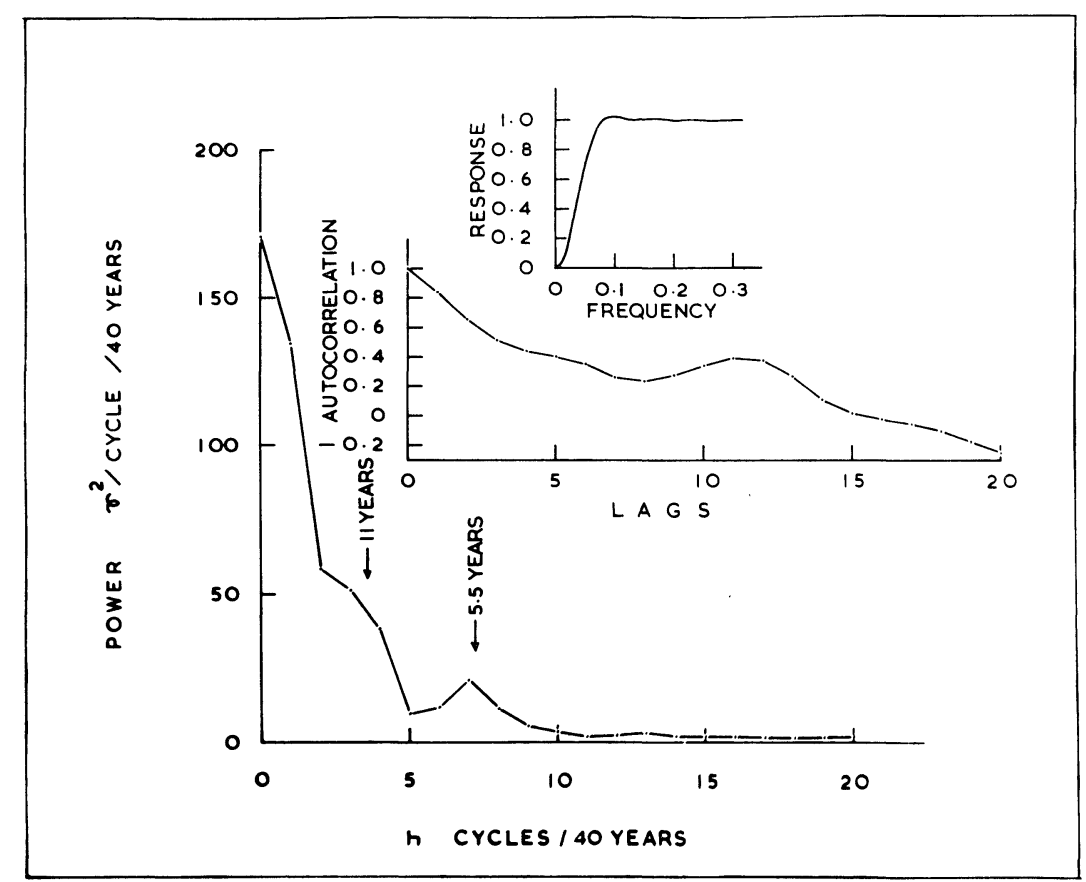

Fig. 4 Autocorrelation function and power spectrum of annual mean values of $H$ at Alibag, after application of a 25-weight high pass filter. Frequency response of the filter is also shown. 

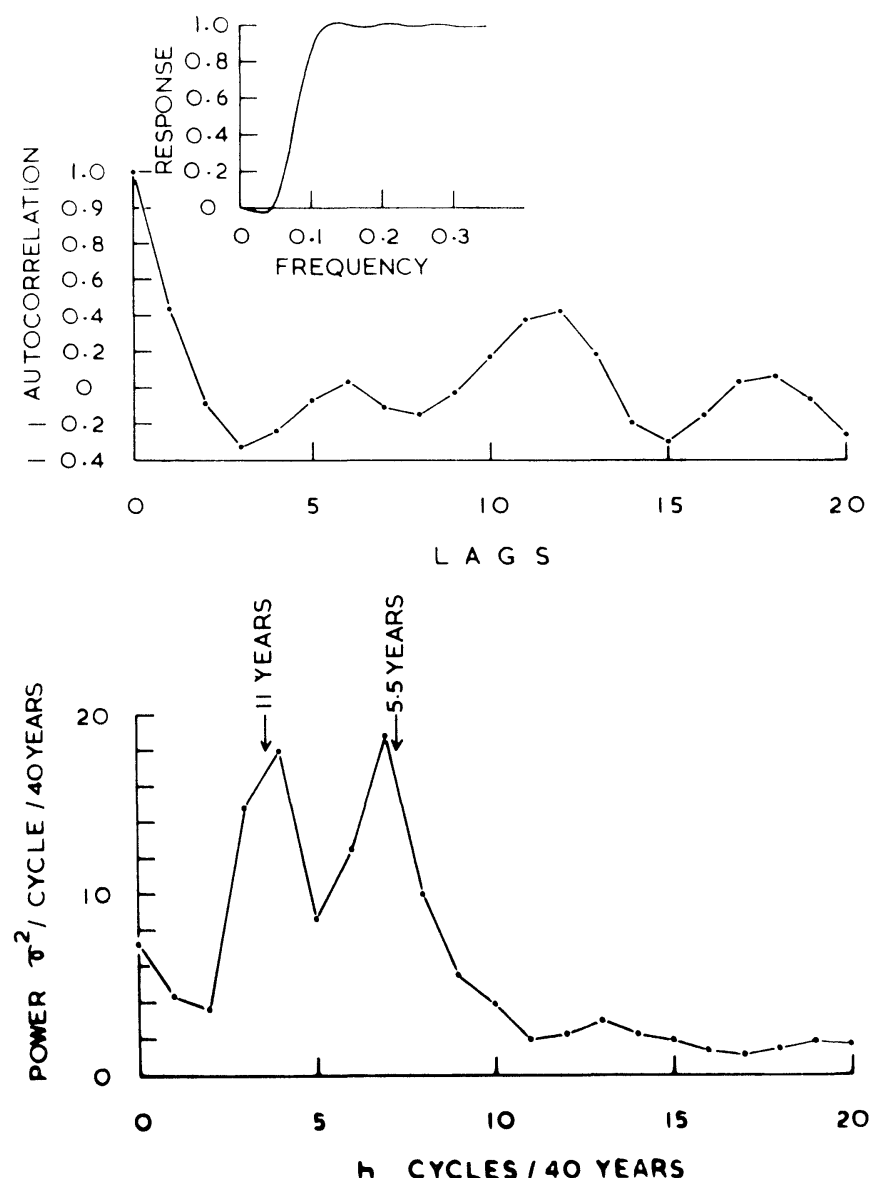

Fig. 5 Autocorrelation function and power spectrum of annual mean values of $H$ at Alibag, after application of a 25-weight shifted high pass filter. Frequency response of the filter is also shown.

To isolate the solar-cycle variation in the series of annual mean values of $H$ at the eight stations a band-pass filter was designed following Behanon and Ness (1966). The response of the 25-point filter is shown in Fig. 1 (Curve B). It is 0.99 for frequency $1 / 11,0.55$ for $1 / 22$, 0.11 for $1 / 50$ and 0.05 for $1 / 6$ cycle/year. The filter thus effectively reduces the amplitudes of components greater than 11 years while passing with practically no attenuation the solarcycle period. Periods greater than 50 years and less than 6 years are practically removed by the filter. In addition to the data series of the eight stations the filter was also applied to a series of mean yearly values of relative sunspot number. The horizontal force at the eight stations after the application of the band-pass filter together with the smoothed sunspot number is shown in Fig. 6. A certain amount of large-period variation persists in the plots of Fig. 6. With a view to eliminate it the band-pass filter was applied a second time to the filtered data. The points, after two applications of the filter, are shown in Fig. 7. 


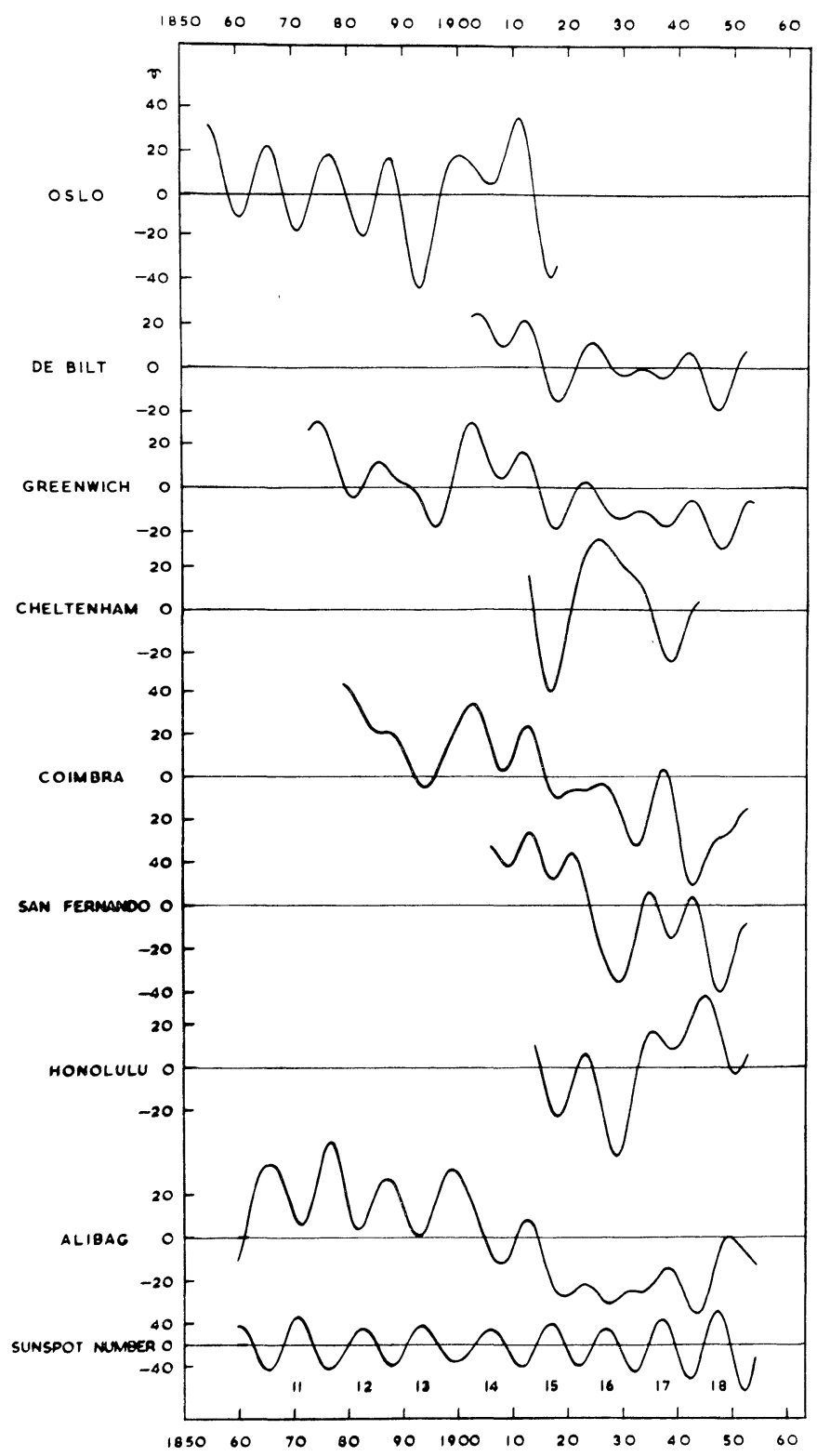

Fig. 6 Solar cycle response of annual mean values of $H$ at eight observatories, after a single application of the 25 -weight band pass filter (response shown in Fig. 1). Smoothed annual mean sunspot numbers from cycles 11 to 18 also appear in the figure.

\section{Results}

From Figs. 6 and 7 it is noticed that horizontal force at all stations, extending in latitude from $19^{\circ} \mathrm{N}$ to $60^{\circ} \mathrm{N}$, shows systematic and periodic or quasiperiodic behavior. The amplitude of the solar-cycle component in the horizontal force is found to be of the same order at all 


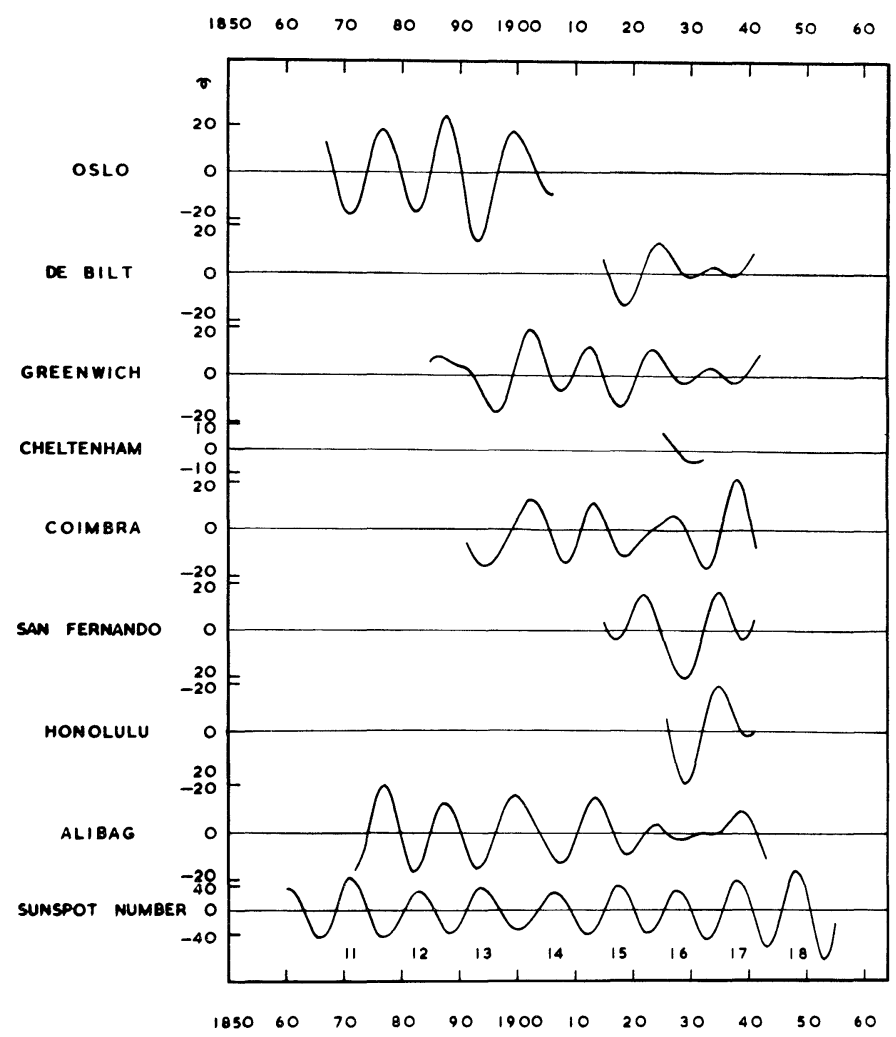

Fig. 7 Solar cycle response of annual mean values of $H$ at eight observatories, after two applications of the 25-weight band pass filter (response shown in Fig. 1). Annual mean sunspot numbers in the figure are the same as shown in Fig. 6.

Table 2. Average Response of $H$ to 11-year Solar Cycle, after application of band-pass filter twice (Fig. 7).

\begin{tabular}{|c|c|c|c|}
\hline Station & $\begin{array}{l}\text { Response } \\
\text { in } \gamma\end{array}$ & $\begin{array}{l}\text { Period of antiphase } \\
\text { variation }\end{array}$ & Remarks \\
\hline Alibag & 28 & $1872-1920$ & $\begin{array}{l}\text { After } 1920 \text { the amplitude is reduced and } \\
\text { variation is not altogether out of phase. }\end{array}$ \\
\hline Honolulu & 30 & $1926-1941$ & \\
\hline San Fernando & 28 & $1915-1941$ & \\
\hline Cheltenham & $(32)$ & $1925-1932$ & $\begin{array}{l}\text { Too short a period. Response is from data } \\
\text { with only one application of the filter. }\end{array}$ \\
\hline Coimbra & 26 & $1891-1918$ & $\begin{array}{l}\text { Variation not altogether out of phase } \\
\text { after } 1918 .\end{array}$ \\
\hline Greenwich & $\left\{\begin{array}{l}18 \\
26\end{array}\right.$ & $\begin{array}{l}1892-1942 \\
1892-1924\end{array}$ & Reduced amplitude after 1924. \\
\hline De Bilt & $\left\{\begin{array}{l}12 \\
20\end{array}\right.$ & $\begin{array}{l}1915-1941 \\
1915-1930\end{array}$ & Reduced amplitude after 1930. \\
\hline Oslo & 42 & $1867-1906$ & \\
\hline
\end{tabular}


stations. The average responese of $H$ to solar activity for the eight stations is given in Table 2. This has been computed by averaging the successive peak to trough and trough to peak ranges in the twice filtered data. The variations are generally, but not everywhere, in phase opposition to solar activity. Long period variations of large amplitudes different from one station to another also appear to be present in the data (Fig. 6). The variations are, therefore, discussed separately for each station.

$4(I)$. Colaba-Alibag (1848-1967).

Corresponding to solar cycles 11,12, 13 and 14, the oscillations of the field are systematic and in phase opposition to sunspot number. During these cycles the minima in the horizontal force, corresponding to peak solar activity, occur within about a year of the peak solar activity. The minima are either coincident or follow the solar activity except for solar cycle 12 when the minimum in horizontal force preceded the solar cycle peak by about a year. With cycle 15, the response, however, undergoes a change, the amplitudes of the oscillations in the horizontal force decreasing very considerably. With the start of cycle 17 , the phase also changes and the field does not decrease with increase in sunspot number. This behaviour is attributed to the presence of a long period ( $\simeq 80$ year) oscillation in the horizontal component which is discussed in section 5. The average response of the horizontal force to solar activity during cycles 11 to 14 is $28 \gamma$.

\section{$4(I I)$. Greenwich-Abinger-Hartland.}

The longest series after Colaba-Alibag is the Greenwich-Abinger-Hartland series, the filtered data being available from 1873 to 1954. The principal characteristics of the horizontal force are a prominent 22-year response of large amplitude corresponding to the odd solar cycles. The field is minimum about 2 years before the peak of cycle 12 and 2 years after the peak of cycle 13 . For cycles 14 to 18 the minimum in the field occurs almost simultaneously with the peak of the solar cycle. The average response of the field to solar cycle is $26 \gamma$. A decrease of the field, from preceding maximum, corresponding to cycles 16 and 17, is small and is similar to variation observed at Colaba-Alibag.

\section{4 (III). Coimbra.}

The filtered data of Coimbra extend from 1879 to 1953. The solar cycle response in the horizontal force between cycles 12 to 15 is in anti-phase with the solar activity. Variations of long periods and large amplitude are superposed on the solar-cycle variation at this station and the anomalous nature of the phase relationship between the horizontal force and solar activity between cycles 16 to 18 appears to be associated with these variations. The average amplitude of the response to 11-year cycle for Coimbra is $26 \gamma$.

$$
4(I V) \text {. Oslo. }
$$

The 11-year variations in the horizontal force at this station are large and very regular over three solar cycles, 10 to 12 . Thereafter a 22 -year variation of a very large magnitude is superposed upon the solar-cycle component. The field is depressed to a much greater extent at epoch corresponding to maxima of odd solar cycles 13 and 15 . The variations of the field are in almost absolute phase opposition to solar activity. The average amplitude of the oscillation is $42 \gamma$. Large period variations do not appear to cause any serious conta- 
mination of the 11-year variation.

\section{$4(V)$. Cheltenham.}

The filtered data of this station extend over a little more than two cycles. An outstanding feature at this station is the 22-year variation in the field with a big response of the horizontal force during odd cycles 15 and 17.

\section{$4(V I)$. San Fernando.}

The filtered data of this station from 1903 to 1953 show a regular response of the field to solar activity throughout the 50 years but the amplitudes vary cons:derably being largest corresponding to cycles 16 and 18. Long-period variations of large magnitude appear in the data of this station also. The average response of the field to the solar cycle from cycle 14 to 18 is $28 \gamma$.

$4(V I I)$. Honolulu.

The filtered data of this station, extending from 1914 to 1953, show a large solar cycle as well as 22-year variation. The solar cycle response in the horizontal force at this station is $30 \gamma$.

\section{$4($ VIII). De Bilt.}

The response of the field at this station between 1903 and 1953, is remarkably similar to Greenwich-Abinger-Hartland. The reduced 11-year response for solar cycles 16 and 17 also follows the pattern at Greenwich-Abinger-Hartland. Between cycles 14 and 18 the response is fairly uniformly in anti-phase with the solar activity except for cycle 16 when the maximum response of the magnetic field occurs about two years after the solar maximum. The average 11-year solar cycle response at this station is $20 \gamma$.

\section{Discussion}

The response of the solar cycle in the horizontal force at the eight stations is fairly uniform. With only one station in low latitude and with contamination of data by large amplitude periodic variations, it is not possible to compare the response at low latitude to that at high latitudes with any confidence. While the decrease in the horizontal component with increase in sunspot number is established the relative phases of the variations are not very consistent in successive solar cycles; the solar cycle peak was mostly followed by minima in the horizontal force but in some cycles it was preceded by it. The response to solar cycle variations, noticed here, varies considerably from one cycle to another for some of the stations. This feature appears to arise from superposed periodicities of large amplitudes which are not completely removed by the filter. The solar cycle response in the horizontal force, observed at the eight stations, except for De Bilt, vary between about 22 and $42 \gamma$. Since the variations are nearly sinusoidal these will correspond approximately to amplitudes of 11 to $21 \gamma$. These figures are of a slightly larger magnitude than those of Yukutake (1965) who obtained the amplitudes in $X$ to be between 2 and $17 \gamma$.

The reduced field during solar maximum has been ascribed to greater magnetic activity during these periods (Vestine at al. 1947). However, from an examination of data of all days and 10 quiet days of each month from Tucson, Yukutake observed that the behaviour 
of $X, Y$ and $Z$ components in both the data sets was similar. He concluded that the 11-year variations were not due to field-diminishing effects of storms during high solar activity. The magnitude of response to solar cycle in the horizontal force has to be considered in relation to several factors.

(i) The magnitude of the solar quiet day variation. This has the effect of increasing the average field at stations between the foci of the northern and southern $S_{q}$ current system and of decreasing the field in the regions north and south of these foci.

(ii) The effect of the solar wind on the quiet day magnetic variations. The quiet day solar wind confines the field to a comet shaped region. As a result of the strain the field at the surface increases. The magnitudes of this increase have been computed by Beard and Jenkins (1962), Midgley and Davis (1963) and Mead (1964). Taking into account the confinement on the night side also, the diurnal variation due to these strains at a station rotating with the earth has been computed to de only about $3.3 \gamma$.

During high solar activity, except for brief periods of increased plasma pressure during the initial phase of storms, the increase of the field arising from quiet-sun wind is perhaps same as during low activity period. The effect of the solar wind, during all periods, should, therefore, result in an increase in the field during high activity and cannot account for the observed decrease.

(iii) The effect of the quiet-time ring current. Since according to Yukutake (1965) the solar-cycle effects are present without diminution of amplitude even during quiet-periods, the decrease of the horizontal component cannot be ascribed to subnormal field associated with storm time ring current. He has ascribed the reduced field to an increase in the current intensity or to a slightly closer approach of the quiet-time ring current (Akasofu, 1963) during periods of increased solar activity. The belt, observed at about $3.2 r_{E}$ (Davis and Williamson, 1963; Frank et al. 1964) is known to be associated with the largest reduction in the field. It is quite likely that the growth and decay of this belt has a long-period component corresponding to a solar cycle. Alternately the decrease of the field as observed could be accounted for by a closer appraoch of the belt to the earth with increased solar activity in the course of a solar cycle. Such a possibility in the quiet-time proton belt can be further investigated from an analysis of night time data of quiet periods from stations where long and systematic observations are available.

The power spectrum shown in Fig. 5 has a well resolved 5.5 year line. Some evidence of this line has been found in power spectrum of geomagntic data by Currie (1966) and in that of relative sunspot numbers by Ward and Shapiro (1961) and Granger and Hatanaka (1964). Since the autocorrelation function (Fig. 5) also shows a peak corresponding to a cyclic component of about 5.5 years and 17-18 years, it is very likely that cyclic components of these periods are present in the series of mean annual values of horizontal force at Colaba-Alibag. The fact that the curve fitted to annual values by Fisk (1931) contained a term corresponding to 16 years and byVestine et al. (1947) a term corresponding to 18 years supports the existence of a 17 or 18 year cycle in the field found in the data of Colaba-Alibag.

Even though variations at 22 years have been largely reduced by the filter, the data of 
most of the stations examined here (Fig. 6) shows greater response of the field (deeper minimum) with alternate odd solar cycle peaks. This variation also noticed by Yukutake (1965) at Tucson, San Juan and Apia is apparently associated with the Hale or double sunspot cycle. It, however, does not appear to be present uniformly over long periods. The data of Oslo, for instance, indicates that the 22-year response was present only after about 1890. Unlike other stations, the maximum response of the field at two of the stations San Fernando and Honolulu appears to be coincident at peaks of even solar cycles 16 and 18. At the low latitude station Colaba-Alibag the oscillation is of a comparatively small amplitude.

The long data series of Colaba-Alibag appear to show an 80 to 90 year cycle (Gleissberg, 1965). A solar-climatic relationship corresponding to this long cycle is known for some time (Willett, 1967). The Colaba-Alibag series, after reducing the trend (Fig. 3), indicates the presence of an oscillation of amplitude between 10 and $25 \gamma$ from the mean even though the periods of about 80 years have been reduced by the trend elimination filter by a factor of 0.2. The oscillation, if real, is therefore of a very large magnitude. The 11-year overlapping means of the filtered data are show in Fig. 3 by circles. It is noticed that from about 1866 to 1904 the field was above average and from 1904 to 1942 it was below average. The former period is fairly conicident with the period during which 30 -year means of the pressure parameters showed a maximum in the Indian Ocean and the latter period (19041942 ) is about the same during which the pressure parameters showed a maximum in the Pacific Ocean (Schove, 1967) indicating yet another link between geomagnetic and climatic features.

\section{References}

Akasofu, S-I., The Main Phase of Magnetic Storms and the Ring Current, Space Sci. Rev., 2, 91, 1963. Banks, R.J. and E.C. Bullard, The Annual and 27 Day Magnetic Variations, Earth. Planet.Sci. Letters., 1, 118, 1966.

Beard, D.B. and E.B. Jenkins, The Magnetic Effects of Magnetosphere Surface Currents, J. Geophys. Res., 67, 3361, 1962.

Behanon, K.W. and N.F. Ness, The Design of Numerical Filters for Geomagnetic Data Analysis, NASA Technical Note TN D-3341, 1966.

Blackman, R.B. and J.W. Tukey, The Measurement of Power Spectra, Dover Publications, New York 1959.

Chapman, S. and J. Bartels, Geomagnetism, I, Oxford University Press, 1940.

Chernosky, E.J., Double Sunspot-cycle Variation in Terrestrial Magnetic Activity, 1884-1963, J. Geophys. Res., 71, 965, 1966.

Currie, R.G., The Gemagnetic Spectrum-40 Days to 5.5 Years, J. Geophys. Res., 71, 4579, 1966.

Davis, L.R. and J.M. Williamson, Low Energy Trapped Protons, Space Res., 3, 365, 1963.

Eckhardt., D.H., K. Larner and T. Madden, Long-Period Magnetic Fluctuations and Mantle Electrical Conductivity Estimates, J. Geophys. Res., 68, 6279, 1963.

Fisk, H.W., Magnetic Secular Variation and Solar Activity, Internat. Res. Council, Third Rept. Comm. on Solar and Terrestrial Relationships, 52, 1931.

Fleming, J.A. and W.E. Scott, List of Geomagnetic Observatories and Thesaurus of Values, J. Terr. Magn. Atmos. Elect., 48, 106, 239, 1943. 
Fleming, J.A. and W.E. Scott, List of Geomagntic Observatories and Thesaurus of Values, J. Terr. Magn. Atmos. Elect., 49, 48, 1944.

Frank, L.A., J.A. Van Allen and H.K. Hills, A Study of Charged Particles in the Earth's Outer Radiation Zone with Explorer 14, J. Geophys. Res., 69, 2171, 1964.

Gleissberg, W., The Eighty-Year Cycle in Auroral Frequency Numbers, J. Brit. Astr. Assoc., 75, 227, 1965.

Granger, C.W.F. and M. Hatanaka, Spectral Analysis of Economic Time Series, Princeton University Press, 1964.

Mead, G.D., Deformation of the Geomagnetic Field by the Solar Wind, J. Geophys. Res., 69, 1181, 1964.

Midgley, J.E. and L. Davis, Calculation by a Moment Technique of the Perturbation of the Geomagnetic Field by the Solar Wind, J. Geophys. Res., 68, 5111, 1963.

Moos, N.A.F., Magnetic Observations made at the Government Observatory, Bombay, for the period 1846-1905 and their Discussion. Pt. II. The Phenomenon and its Discussion, Bombay, Government Central Press, 1910.

Pramanik, S.K. and M.K. Ganguli, Sunspots and Geomagnetic Variations, Indian J. Met. Geophys., 5, 161, 1954.

Schove, D.J., Sunspot Cycles, The Encyclopedia of Atmos. Sci. and Astrogeology, (Reinhold), 967, 1967.

Vestine, E.H., I. Lange, L. Laporte and W.E. Scott, The Geomagnetic Field, Its Description and Analysis, Pub. Carnegie Inst. of Washington, No. 580, 85, 1947.

Ward, F. and R. Shapiro, Solar Geomagnetic and Meteorological Periodicities, Ann. N.Y. Acad. Sci., 95, 200, 1961.

Wasserfall, K.F., Magnetic Horizontal Intensity at Oslo 1843-1930, J. Terr. Magn. Atmos. Elect., 46, 173, 1941.

Willet, H.C., Solar-Climatic Relationships, The Encyclopedia of Atmos. Sci. and Astrogeology (Reinhold,) 869, 1967.

Yukutake, T., The Solar Cycle Contribution to the Secular Change in the Geomagnetic Field, J. Geomag. Geoelect., 17, 287, 1965. 